\title{
Tolmetin Sodium
}

National Cancer Institute

\section{Source}

National Cancer Institute. Tolmetin Sodium. NCI Thesaurus. Code C61977.

The sodium salt form of tolmetin, an arylalkanoic acid and non-steroidal antiinflammatory drug (NSAID) with analgesic, anti-inflammatory and antipyretic activities. Although the exact mechanism through which tolmetin exerts its effects has yet to be fully elucidated, this agent appears to inhibit the enzyme prostaglandin synthase. This prevents the formation of prostaglandins from prostaglandin precursors, including the synthesis of the inflammatory prostaglandin E2 (PGE2) from the precursor prostaglandin H2 (PGH2). This prevents prostaglandin-mediated effects, including pain, inflammation and fever. 